\title{
Analysis of 30 years rainfall variability in Imo State of southeastern Nigeria
}

\section{FIDELIS CHINAZOR OKORIE}

Department of Geography and Environmental Management, Imo State University, PMB 2000, Owerri, Imo State, Nigeria chinazorfiddy@hotmail.com

Many variations in rainfall have occurred for different climatic regions and individual locations in Nigeria with associated disasters. Every rainy season in Nigeria, wind gusts arising from tropical storms claim lives and properties worth millions of naira across the country. Flash floods from torrential rains wash away thousands of hectares of farmland. Dam bursts are common following such floods. Rainfall is one of the atmospheric driving forces responsible for climate variation and its effects in Imo state of Nigeria as in other parts of the world. A study in 2009 indicated that about $16 \%$ of the erosion in Owerri Municipality of Imo State is caused by rainfall (Maduka, 2009). Other current research shows that $91 \%$ of malaria cases in Orlu, Imo State, are attributed to rainfall variability (Okorie et al. 2014), which means that rainfall promotes mosquito breeding. The aim of this research is to analyse variability in rainfall in Imo State of Nigeria over 30 years. Ground truth precipitation data for 1980-2009 acquired from Nigeria Meteorological Department were used. The results show many variations in rainfall within the period under study, which have caused some environ-hydrological problems including coastal erosion, flooding and flood-related disasters (such as pollution, increased disease vectors, communicable diseases and epidemics). Such hydrological problems are the effects of climate variation induced by rainfall anomalies.

Imo State is located between latitude $4^{\circ} 45^{\prime} \mathrm{N}$ and $7^{\circ} 15^{\prime} \mathrm{N}$ and longitude $6^{\circ} 50^{\prime} \mathrm{E}$ and $7^{\circ} 25^{\prime} \mathrm{E}$, with an area of about $5100 \mathrm{~km}^{2}$. It lies within the humid tropics and is generally characterized by a high surface air temperature regime year-round. Mean minimum temperature is $23.5^{\circ} \mathrm{C}$ and mean maximum temperature is $32.1^{\circ} \mathrm{C}$. Two seasons, wet and dry, are observed in the year. The rainy seasons begin in April and lasts till October. The State experiences climate variations following rainfall variability. It is on this premise therefore, that this study focused on determination of the shifts in rainfall and the associated disasters as the evidence of climate variation in Imo State.

\section{METHODOLOGY}

Mean monthly rainfall data from Owerri synoptic station between 1980 and 2009 converted to annual mean were collected from the Nigerian Meteorological Department, Lagos (Table 1). Rainfall data is used in this study as an indication of rainfall being a key climatic variable. The research covers one climatic period of 30 years that provides a better platform to investigate the variability and changes in the climate systems in the study area. The mean annual rainfall data were used to construct a rainfall chart of the state for the climatic period (Fig. 1) and with the chart, the analysis of the pattern and trends of rainfall in the area was carried out.

\section{RESULTS AND DISCUSSION}

This study established that there is variability in the weather and climate system of Imo State due to the observed shifts in rainfall within the 30 -year climatic period. For example, the average mean rainfall in Table 1 from 1980 to 1982 was the same 3.4\%, but in 1983, there was sharp decline in rainfall with the mean $2.2 \%$, and in 1984 it increased to $3.0 \%, 1985,3.4 \%$ and $1986,3.5 \%$. In 1987 it dropped to $2.9 \%$ and rose to $3.6 \%$ in $1988 / 89$, then in 1990 it rained heavily with $4.2 \%$ and dropped to $3.5 \%$ in 1991, and remained high for 7 years till 1998 when it declined to $2.3 \%$. In 1999 it shifted to $3.5 \%$ and remained high above $3.0 \%$ throughout, except in 2002 with $2.9 \%$, 2004 with $2.5 \%$ and in 2009 with $2.9 \%$.

This research ascertained that the shifts and variability in rainfall over the state within the period under study show some evidence of climate variations and change in the climate of the area. 
Table 1 Rainfall data for Imo State, 1980-2009 (Owerri synoptic station).

\begin{tabular}{|c|c|c|c|c|c|c|c|}
\hline Year & $\begin{array}{l}\text { Total RF } \\
(\mathrm{mm})\end{array}$ & $\begin{array}{l}\text { Monthly } \\
\text { mean (mm) }\end{array}$ & $\begin{array}{l}\text { Mean/30-year } \\
\text { total }(\%)\end{array}$ & Year & $\begin{array}{l}\text { Total RF } \\
(\mathrm{mm})\end{array}$ & $\begin{array}{l}\text { Monthly } \\
\text { mean (mm) }\end{array}$ & $\begin{array}{l}\text { Mean/30-year } \\
\text { total }(\%)\end{array}$ \\
\hline 1980 & 2398.2 & 199.9 & 3.4 & 1995 & 2622.3 & 219 & 3.7 \\
\hline 1981 & 2432.7 & 202.7 & 3.4 & 1996 & 2705.5 & 225 & 3.8 \\
\hline 1982 & 2404.3 & 200.4 & 3.4 & 1997 & 2891.4 & 241 & 4.1 \\
\hline 1983 & 1557.9 & 129.8 & 2.2 & 1998 & 1640.1 & 136.7 & 2.3 \\
\hline 1984 & 2153.2 & 179 & 3.0 & 1999 & 2515.4 & 209.6 & 3.5 \\
\hline 1985 & 2396.1 & 199.7 & 3.4 & 2000 & 2337.2 & 195 & 3.3 \\
\hline 1986 & 2482.9 & 206.9 & 3.5 & 2001 & 2304.3 & 192 & 3.2 \\
\hline 1987 & 2075.5 & 173 & 2.9 & 2002 & 2053.7 & 171 & 2.9 \\
\hline 1988 & 2563.7 & 213.6 & 3.6 & 2003 & 2327.8 & 194 & 3.3 \\
\hline 1989 & 2581.5 & 215 & 3.6 & 2004 & 1762.3 & 147 & 2.5 \\
\hline 1990 & 2961.3 & 246.8 & 4.2 & 2005 & 2236.6 & 186.4 & 3.1 \\
\hline 1991 & 2567.4 & 210.6 & 3.5 & 2006 & 3209.1 & 267 & 4.5 \\
\hline 1992 & 2424.1 & 202 & 3.4 & 2007 & 2361.6 & 197 & 3.3 \\
\hline 1993 & 2182.8 & 181.9 & 3.1 & 2008 & 2470.2 & 205.9 & 3.5 \\
\hline 1994 & 2626 & 219 & 3.7 & 2009 & 2092.8 & 174.4 & 2.9 \\
\hline & & & & \multicolumn{2}{|c|}{ Total 1980 to 2009} & 6110.5 & \\
\hline
\end{tabular}

Source: Field Survey 2011; NIMET 2011, Lagos, Nigeria

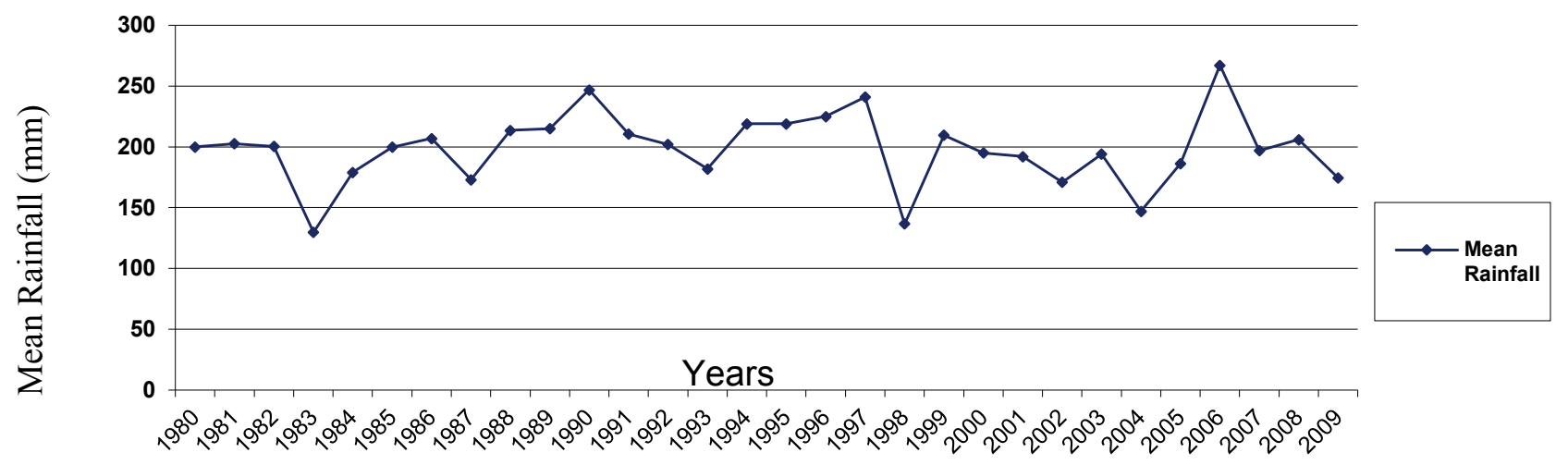

Fig. 130 years (1980-2009) rainfall variability curve in Imo State.

\section{CONCLUSION}

The Earth has experienced cycles of temperature and precipitation changes on a geological scale. The overlying mechanism for the various changes in weather and climate system is related to restless atmospheric processes, which are always in a delicate state of equilibrium. Nnaji (1998) reported that variations in rainfall intensified for the different climatic regions and individual locations in Nigeria in the last three decades of the last century. However, this study indicates that there is variation in the climate of Imo State following rainfall variability and a lot of negative impacts have been created by this climatic phenomenon in the area.

\section{REFERENCES}

Maduka, E.C. (2010) Soil erosion in Owerri Municipal: Causes and effects. Unpublished BSc Project. Geography and Environmental. Management, Imo State University, Owerri, Nigeria.

Nnaji, A.O. (2009) Implications of current climate variation on weather conditions over Imo State. Journal of Biological and Environmental Sciences 2, 22-23.

Okorie, F. C., Ezedike C.E. and Chibo, C.N. (2014) Influence of climate variability on mosquitoes bite in Orlu area of Imo state Nigeria. Proceedings of Association of American Geographers Meeting, 7-12 April 2014, Tampa, Florida, USA.

Okorie, F.C., et al. (2011) Rainfall variability as evidence of climate variation in Imo State of south-eastern Nigeria. International Journal of Sustainable Development 4(9).

Okorie, F.C., et al. (2012) Evidence of climate variability in Imo State of southeastern Nigeria. Proceedings of the 5th International Conference on Water, Climate and Environment. BALWOIS 2012, Ohrid, Republic of Macedonia, http://www.balwois.com/2012/. Journal of Earth Science and Engineering 2, 544-553. 